\title{
HUBUNGAN PERILAKU PEMBERIAN MAKANAN PENDAMPING ASI DENGAN STATUS GIZI BAYI USIA 6-11BULAN DI WILAYAH BEJI SIDOARUM GODEAN SLEMAN
}

\author{
RELATIONSHIP BEHAVIOR PROVIDING FOOD OF ASSEMBLY STUDENTS \\ WITH NUTRITION STYLE BABY AGE 6-11 MONTH IN THE BEJI SIDOARUM \\ GODEAN SLEMAN
}

\section{Enny Fitriahadi}

Program Studi Bidan Pendidik Jenjang D-IV

Universitas 'Aisyiyah Yogyakarta

E-mail : ennyfitriahadi@rocketmail.com

\begin{abstract}
ABSTRAK
Masalah gizi adalah hal yang sangat penting dan mendasar bagi kehidupan manusia. Kekurangan gizi selain dapat menimbulkan masalah kesehatan (morbiditas, mortalitas dan disabilitas), juga menurunkan kualitas sumber daya manusia (SDM) suatu bangsa. Dalam skala yang lebih luas, kekurangan gizi dapat menjadi ancaman bagi ketahanan dan kelangsungan hidup suatu bangsa (Depkes, 2013). Menurut laporan dinas kesehatan Propinsi DIY tahun 2013, jumlah prevalensi gizi buruk yang ditemukan di kota Gunung Kidul 4,7\%, Yogyakarta 4,3\%, Sleman 5,5\%, Bantul 2,1\%,dan Kulon Progo 2,4\%. Tujuan dari penelitian ini untuk mengetahui hubungan perilaku pemberian makanan pendamping ASI dengan status gizi pada bayi usia 6-11 bulan di Wilayah Beji Sidoarum Godean Sleman. Metode penelitian menggunakan survey analitik yaitu suatu penelitian yang mencoba menggali bagaimana dan mengapa fenomena kesehatan itu terjadi. Pengambilan sampel dilakukan secara menggunakan Simple Random Sampling dilakukan secara acak tanpa memperhatikan strata yang ada. Metode Penelitian : Penelitian ini merupakan penelitian kuantitatif, dengan metode survey analitik yaitu suatu penelitian yang mencoba menggali bagaimana dan mengapa fenomena kesehatan itu terjadi dengan pendekatan cross sectional. Teknik pengambilan sampel dalam penelitian ini adalah teknik sampling jenuh. Sampel berjumlah 57 bayi. Analisis data menggunakan chi square. Hasil Penelitian : Berdasarkan hasil uji Chi Square yaitu p-value yang diambil dari pearson Chi-Square yaitu 0.000. sehingga p-value $0.000<0.05$ dapat disimpulkan ada hubungan perilaku pemberian makanan pendamping ASI dengan status gizi bayi usia 6-11 bulan di wilayah Beji Sidoarum Godean Tahun 2017. Saran bagi ibu diharapkan lebih aktif lagi dalam menggali informasi yang benar tentang pemberian makanan pendamping ASI sehingga ibu dapat memberikan makanan pendamping ASI dengan tepat waktu.
\end{abstract}

Kata kunci : Perilaku Pemberian MP-ASI, Status Gizi

\section{ABSTRACT}

Nutrition problem is very important and fundamental to human life. Malnutrition but can cause health problems (morbidity, mortality and disability), it also lowers the quality of human resources (HR) of a nation. In a broader scale, malnutrition can be a threat to the sustainability and survival of a nation (MOH, 2013). According to the health department of DIY in 2013, the prevalence of malnutrition were found in the town of Gunung Kidul 4.7\%, 4.3\% Yogyakarta, Sleman 5.5\%, 2.1\% Bantul and Kulon Progo 2.4\%. The purpose of this study to determine the relationship of complementary feeding behavior and nutritional status in infants aged 6-11 months in Beji Sidoarum Godean Sleman region. The research method uses analytical survey of a study which tried to explore how and why health phenomenon that happens. Sampling was done by using Simple Random Sampling is done randomly without regard to existing strata.

Methods: This study is a quantitative, analytical survey method is a study which tried to explore how and why health phenomenon that occurs with cross sectional approach. The sampling technique in this research is saturated sampling technique. Sample of 57 infants. The data analysis using chi square. Results: Based on the chi-square test p-value is taken from Pearson Chi-Square 
is 0.000. so that the p-value 0.000> 0.05 can be concluded that there is a relationship complementary feeding behavior and nutritional status of infants aged 6-11 months in the region of Godean Sidoarum Beji Year 2017. Suggestions for the mother is expected to be more active in tapping the correct information regarding the provision of complementary feeding so that the mother can give complementary foods in a timely manner. The target of this research was to determine the behavior of the provision of complementary foods with nutritional status of infants aged 6-11 months, in addition to the outcomes in this study is to produce an article published in a national journal is a journal nursing and midwifery Faculty of Health Sciences University 'Aisyiyah Yogyakarta.

Keywords: Behavior Giving breastfeeding, Nutritional Status

\section{PENDAHULUAN}

Masalah gizi adalah hal yang sangat penting dan mendasar bagi kehidupan manusia. Kekurangan gizi selain dapat menimbulkan masalah kesehatan (morbiditas, mortalitas dan disabilitas), juga menurunkan kualitas sumber daya manusia (SDM) suatu bangsa. Dalam skala yang lebih luas, kekurangan gizi dapat menjadi ancaman bagi ketahanan dan kelangsungan hidup suatu bangsa (Depkes, 2013).

Gizi merupakan salah satu indikator derajat kesehatan masyarakat. Penilaian Indikator status gizi melihat dari penimbangan bayi usia 6-11 bulan apakah sesuai dengan Umur, presentasi $\mathrm{D} / \mathrm{S}$ setiap bulannya sesuai target (Supariasa, 2012). Gizi yang baik sangat penting untuk pertumbuhan bayi dan balita karena dapat mempengaruhi pembentukan organ dan fungsinya, serta fungsi saraf, dan sistem kekebalan tubuh Terdapat kaitan yang sangat erat antara status gizi dengan konsumsi makanan. Pemberian makanan yang kurang baik akan menyebabkan gangguan gizi pada bayi seperti obesitas, gizi kurang, gizi buruk, dan stunting. Gangguan gizi dapat menurunkan intelegensia pada bayi dan balita serta menurunkan daya tahan tubuh terhadap berbagai penyakit, terutama penyakit infeksi seperti ISPA, diare, typus, dll.

Propinsi DIY merupakan daerah cakupan pelayanan kesehatan tertinggi, dan angka gizi kurang di DIY telah jauh melampaui target nasional. Namun penderita gizi buruk masih dijumpai diwilayah DIY. Prevalensi gizi kurang dikota Yogyakarta masih tinggi yaitu $7,7 \%$, sedangkan prevalensi gizi kurang di kabupaten Sleman 10\%, Kulon Progo 9,9\%, Gunung Kidul 16,4\% dan Bantul 15,5\%. Gizi buruk yang makin meningkat pertahun di DIY menambah peluang bayi atau balita yang mengalami gizi kurang untuk menjadi gizi buruk, Tahun 2013 $12,2 \%$ balita mengalami gizi kurang yang akan terus bertambah jika tidak ditangani secara menyeluruh dan terpadu (Dinkes DIY, 2013). Menurut laporan dinas kesehatan Propinsi DIY tahun 2013, jumlah prevalensi gizi buruk yang ditemukan di kota Gunung Kidul 4,7\%, Yogyakarta 4,3\%, Sleman 5,5\%, Bantul 2,1\%,dan Kulon Progo 2,4\% (profil kesehatan DIY, 2013).

Penyebab utama terjadinya gizi kurang dan hambatan pertumbuhan pada anak-anak usia 315 bulan berkaitan dengan rendahnya pemberian ASI dan buruknya praktek pemberian makanan pendamping ASI. Berbagai masalah 
yang ada dalam gizi bayi tidak mendiamkan pemerintah untuk membuat sebuah kebijakan untuk menurunkan angka permasalahan yang ada,upaya tersebut dapat terlihat di antaranya melalui revitalisasi Posyandu dalam meningkatkan cakupan penimbangan balita, penyuluhan dan pendampingan, pemberian Makanan Pendamping ASI (MP-ASI) atau Pemberian Makanan Tambahan (PMT), peningkatan akses dan mutu pelayanan gizi melalui tata laksana gizi buruk di puskesmas perawatan dan rumah sakit, penanggulangan penyakit menular dan pemberdayaan masyarakat melalui Keluarga Sadar Gizi (Kadarzi).

Global Strategy for Infant and Young Child Feeding (GSIYCF), WHO/UNICEF merekomendasikan empat hal penting yang harus dilakukan untuk mencapai tumbuh kembang optimal pada anak, yaitu : memberikan air susu ibu kepada bayi segera setelah bayi lahir, memberikan hanya air susu ibu (ASI) saja atau pemberian ASI secara eksklusif sejak lahir sampai bayi berusia 6 bulan, memberikan makanan pendamping air susu ibu (MP-ASI) sejak bayi berusia 6 bulan sampai 24 bulan, meneruskan pemberian ASI sampai anak berusia 24 bulan atau lebih. Rekomendasi tersebut menekankan, secara sosial budaya MP-ASI hendaknya dibuat dari bahan pangan yang murah dan mudah diperoleh di daerah setempat (indigenous food) (Azwar, 2007).

Sujono (2012) menyatakan ASI merupakan makanan yang didapatkan bayi hingga berumur 6 bulan dan mendapatkan Makanan Pendamping ASI kadang diberikan sebelum bayi berumur 6 bulan, hal ini terjadi karena ibu kurang mengetahui tentang pemberian makanan pendamping ASI yang benar, disamping itu beberapa faktor seperti status pekerjaan ibu menjadi alasan ibu memberikan makanan pendamping ASI terlalu dini sehingga dapat meningkatkan angka kematian bayi, mengganggu sistem pencernaan pada bayi, dan apabila terlambat memberikan juga akan membuat bayi kekurangan gizi).

Sulistiyanti

menunjukkan bahwa anak yang memiliki status gizi kurang/gizi buruk disebabkan oleh MP-ASI, permasalahan pemberian MP-ASI pada bayinya yaitu pemberian terlalu dini,pemberian terlambat, frekuensi dan porsi yang tidak sesuai umur baik jenis maupun kualitasnya. Kekurangan tersebut dipengaruhi oleh peningkatan beban kerja perempuan, status sosial, ekonomi, budaya, dan tradisi.

Keluarga menjadi fokus perhatian untuk memaksimalkan potensi anak. Pengetahuan dan kesadaran dari keluarga dan masyarakat untuk memenuhi kebutuhan esensial anak, yaitu kebutuhan gizi, pelayanan kesehatan, kasih sayang, stimulasi perkembangan, pendidikan dan perlindungan anak memegang peranan yang sangat penting (Depkes RI, 2011).

Menurut Simanjutak (2007) makanan pendamping ASI merupakan peralihan dari ASI ke makanan keluarga. Pengenalan pemberian makanan pendamping ASI harus dilakukan secara bertahap baik bentuk maupun jumlah sesuai dengan kemampuan pencernaan 
bayi. Waktu pemberian makanan pendamping ASI pada bayi dilihat dari aspek fisiologi, psikologi, dan kebutuhan gizinya. Waktu yang paling tepat dalam memperkenalkan makanan pendamping ASI pada bayi yaitu ketika bayi berusia 6 bulan.

\section{METODE PENELITIAN}

Penelitian ini merupakan penelitian kuantitatif, dengan metode survey analitik yaitu suatu penelitian yang mencoba menggali bagaimana dan mengapa fenomena kesehatan itu terjadi (Notoatmojo, 2012). Penelitian ini dilakukan untuk mengetahui hubungan perilaku pemberian makanan pendamping ASI dengan status gizi bayi usia 6-11 bulan yang dilakukan di wilayah Beji Sidoarum Godean Sleman. Pendekatan waktu yang digunakan adalah pendekatan secara cross sectional yaitu penelitian yang dilakukan untuk mempelajari dinamika korelasi antara faktorfaktor resiko dengan efek, cara pengumpulan datanya sekaligus pada suatu waktu (Notoatmodjo, 2012).

Populasi dalam penelitian ini adalah ibu yang mempunyai bayi berumur 6-11 bulan yang berdomisili di wilayah Beji Sidoarum Godean Sleman yang berjumlah 57 bayi. Sampel adalah bagian populasi yang akan diteliti atau sebagian jumlah dari karakteristik yang dimiliki oleh populasi (Hidayat, 2007). Teknik pengambilan sampel dalam penelitian ini adalah total sampling yaitu teknik penentuan sampel bila semua anggota populasi digunakan sebagai sampel (Sugiyono, 2011). Sampel adalah seluruh bayi yang berumur 6-11 bulan di wilayah Beji Sidoarum Godean Sleman.

Alat yang digunakan dalam penelitian ini adalah berupa kuesioner atau angket untuk melihat perilaku pemberian makanan pendamping ASI. Untuk mengetahui status gizi yaitu menggunakan timbangan berat badan dengan melihat indikator $\mathrm{BB} / \mathrm{U}$ pada setiap bayi umur 6-11 bulan yang menjadi responden. Analisa yang digunakan adalah Chi Square dengan a 0,05.

\section{HASIL DAN PEMBAHASAN}

a. Karakter Responden Berdasarkan

Tingkat Pendidikan Ibu

Tabel 1

Distribusi frekuensi karakteristik berdasarkan Tingkat Pendidikan Ibu

\begin{tabular}{lcc}
\hline \multicolumn{1}{c}{ Kategori } & Frekuensi & Prosentase (\%) \\
\hline SMP & 12 & 21.0 \\
SMA/SMK & 29 & 50.8 \\
PT & 16 & 28.0 \\
Total & 57 & 100.0 \\
\hline
\end{tabular}

Sumber : Data Primer, 2017

Berdasarkan tabel diatas menunjukkan bahwa sebagian besar responden dengan tingkat pendidikan SMA/SMK dengan jumlah 29 responden $(21.0 \%)$ dan PT (Perguruan Tinggi) berjumlah 16 responden (50.8\%) sebagian kecil responden dengan tingkat pendidikan SMP dengan jumlah 12 responden (28.0\%). 
b. Karakter Responden Berdasarkan Pekerjaan Ibu

Tabel 2

Distribusi frekuensi karakteristik berdasarkan pekerjaan ibu

\begin{tabular}{lcc}
\hline \multicolumn{1}{c}{ Kategori } & Frekuensi & $\begin{array}{c}\text { Prosentase } \\
(\%)\end{array}$ \\
\hline IRT & 44 & 77.2 \\
Dagang/swasta & 9 & 15.7 \\
Guru & 4 & 7.0 \\
Total & 57 & 100.0 \\
\hline
\end{tabular}

Sumber : Data Primer Diolah, 2017

Berdasarkan tabel diatas menunjukkan bahwa sebagian besar responden dengan status pekerjaan sebagai Ibu Rumah Tangga (IRT) dengan jumlah 44 responden $(77.2 \%)$ dan pedagang/swasta berjumlah 9 responden (15.7\%) sebagian kecil responden dengan pekerjaan sebagai guru dengan jumlah 4 responden (7.0\%).

\section{Perilaku Pemberian Makanan Pendamping ASI}

Tabel 3 Tabel distribusi frekuensi pemberian makanan pendamping ASI

\begin{tabular}{llll}
\hline No & $\begin{array}{l}\text { Perilaku } \\
\text { pemberian } \\
\text { makanan } \\
\text { pendamping }\end{array}$ & Frekuensi & Presentase \\
& ASI & & \\
\hline 1 & Tidak Tepat & 13 & $22,8 \%$ \\
2 & Tepat & 44 & $77.2 \%$ \\
\hline & Total & $\mathbf{5 7}$ & $\mathbf{1 0 0 \%}$ \\
\hline
\end{tabular}

Sumber : Data primer, 2017

Berdasarkan tabel diatas menunjukkan bahwa sebagian besar perilaku pemberian makanan pendamping ASI dengan tidak tepat berjumlah $45 \quad(78.9 \%)$ sedangkan perilaku pemberian makanan pendamping ASI yang tepat berjumlah $12(21.0 \%)$.

\section{Status Gizi}

Tabel 4 Tabel distribusi frekuensi status gizi

\begin{tabular}{llll}
\hline No & Status gizi & Frekuensi & Presentase \\
\hline 1 & Gizi buruk & 0 & 0 \\
2 & Gizi kurang & 26 & $45.6 \%$ \\
3 & Gizi baik & 25 & $43.8 \%$ \\
4 & Gizi lebih & 6 & $10.5 \%$ \\
\hline & Total & $\mathbf{5 7}$ & $\mathbf{1 0 0 \%}$ \\
\hline
\end{tabular}

Sumber: Data primer, 2017

Berdasarkan tabel diatas menunjukkan bahwa sebagian besar status gizi bayi adalah gizi kurang $26(45,6 \%)$, gizi baik $25(43,8 \%)$, gizi lebih $6(10,5 \%)$, dan gizi buruk 0 $(0 \%)$. 
3. Hubungan pemberian pendamping status gizi pada bayi usia $6-11$ bulan

Tabel 5 Tabulasi silang hubungan perilaku pemberian makanan pendamping ASI dengan status gizi pada bayi usia 6-11 bulan di wilayah

Beji Sidoarum Godean Sleman.

\begin{tabular}{|c|c|c|c|c|c|c|}
\hline \multirow{3}{*}{$\begin{array}{c}\text { Status } \\
\text { gizi }\end{array}$} & \multirow{2}{*}{\multicolumn{2}{|c|}{$\begin{array}{l}\text { Perilaku } \\
\text { MP-ASI } \\
\text { Tepat }\end{array}$}} & \multicolumn{2}{|c|}{ pemberian } & \multicolumn{2}{|c|}{ Total } \\
\hline & & & \multicolumn{2}{|c|}{$\begin{array}{l}\text { Tidak } \\
\text { Tepat }\end{array}$} & \multirow[b]{2}{*}{$\mathrm{f}$} & \multirow[b]{2}{*}{$\%$} \\
\hline & $\mathrm{F}$ & $\%$ & $\mathrm{~F}$ & $\%$ & & \\
\hline $\begin{array}{l}\text { Gizi } \\
\text { buruk }\end{array}$ & 0 & 0 & 0 & 0 & 0 & 0 \\
\hline $\begin{array}{l}\text { Gizi } \\
\text { kurang }\end{array}$ & 13 & $29,5 \%$ & 13 & $100 \%$ & 26 & $45,6 \%$ \\
\hline $\begin{array}{l}\text { Gizi } \\
\text { baik }\end{array}$ & 25 & $56,8 \%$ & 0 & 0 & 25 & $43,8 \%$ \\
\hline $\begin{array}{l}\text { Gizi } \\
\text { lebih }\end{array}$ & 6 & $13,6 \%$ & 0 & 0 & 6 & 0 \\
\hline Total & 44 & $77,2 \%$ & 13 & $100 \%$ & 57 & $100 \%$ \\
\hline
\end{tabular}

Sumber : Data primer, 2017

Berdasarkan tabel 4.5 tersebut menunjukkan bahwa responden dengan status gizi kurang dengan perilaku pemberian ASI tepat sebanyak 25 responden (56,8\%), sedangkan status gizi baik yang pemberiannya tidak tepat sebanyak 0 responden $(0 \%)$. Status gizi kurang yang memberikan ASI tepat sebanyak 13 responden (29,5\%), sedangkan status gizi kurang yang tidak memberikan ASI tepat sebanyak 13 responden (100\%). Status gizi yag lebih dengan pemberian ASI tepat sebanyak 6 responden $(13,6 \%)$, dan stsus gizi buruk yang memberikan ASI tepat dan tidak tepat sebanyak 0 responden (0\%). Hasil uji Chi
Square yaitu p-value yang diambil dari pearson Chi-Square yaitu 0.000 . sehingga $p$-value $0.000<$ 0.05 dapat disimpulkan ada hubungan perilaku pemberian makanan pendamping ASI dengan status gizi bayi usia 6-11 bulan di wilayah Beji Sidoarum Godean Tahun 2017.

Nilai koefisien kontingensi didapatkan hasil bahwa $\mathrm{C}=0,455$. Dengan demikian dapat disimpulkan bahwa keeratan hubungan koefisien kontingensi adalah sedang (0,40-0,599).

\section{Karakteristik Responden}

Tabel 1 menunjukkan bahwa karakteristik responden berdasarkan pendidikan ibu yang mayoritas berpendidikan SMA/SMK 29 (50,8\%). Tingkat pendidikan yang baik akan mempengaruhi perilaku ibu dalam memberikan makanan pendamping ASI. Sehingga ibu dapat memberikan makanan pendamping ASI tepat pada waktunya (Novita, 2015).

Menurut Handayani (2012) tingkat pendidikan juga berpengaruh terhadap keinginan individu untuk memberikan makanan yang terbaik pada anak. Berbagai penelitian telah membuktikan bahwa tingkat pendidikan berpengaruh terhadap peningkatan pengetahuan. Penelitian di Kenya menunjukkan bahwa responden yang berpendidikan tinggi secara signifikan berpeluang lebih tinggi dibandingkan dengan responden yang berpendidikan rendah, sedangkan responden yang tidak sekolah mempunyai peluang yang sangat kecil untuk dapat menerima informasi yang diberikan. 
Berdasarkan karakteristik pekerjaan ibu responden paling banyak adalah ibu rumah tangga 44 $(77,2 \%)$.

Suatu pekerjaan dapat mempengaruhi responden dalam memberikan makanan pendamping ASI. Responden dengan jam kerja yang padat dalam memberikan makanan pendamping ASI akan kurang maksimal. Misalnya dengan ibu yang bekerja akan mempengaruhi jadwal pemberian makanan pendamping ASI di banding ibu yang tidak bekerja.

\section{Perilaku Pemberian Makanan Pendamping ASI}

Berdasarkan tabel 3 yang telah dijabarkan diatas, diperolah hasil dari 57 responden yang memberikan makanan pendamping ASI, sebanyak 44 responden $(77,2 \%)$ dengan pemberian tepat dan 13 responden $(22,8 \%)$ dengan pemberian tidak tepat. Data ini menunjukkan bahwa sebagian besar bayi di wilayah Beji Sidoarum Godean diberikan makanan pendamping ASI dengan tepat waktu.

Menurut Krisnatuti (2005) perilaku pemberian MP-ASI merupakan tahap awal pemberian MP-ASI, perkenalkan bubur saring dan sari buah 2 (dua) kali sehari sebanyak 1-2 sendok makan penuh. Frekuensi pemberian pendamping ASI lambat-laun harus ditingkatkan sesuai dengan umur bayi. Menginjak usia bayi 7-9 bulan, bayi dapat diberikan makanan 3-6 sendok makan penuh tiap kali makan paling sedikit 4 kali sehari. MP-ASI harus tetap diberikan kepada bayi sampai berusia dua tahun atau lebih.
Dalam Islam telah dijelaskan tentang perintah Allah SWT kepada manusia untuk menjaga makanannya, sebagaimana yang dijelaskan dalam QS 'Abasa (80):24

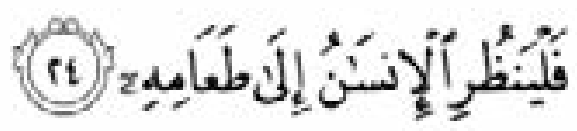

"maka hendaklah manusia itu memperhatikan makanannya .(QS.Abasa: 24)

Ayat diatas menegaskan bahwa umat muslim hendaknya mengkonsumsi makanan yang halal dan bersih karena dapat menghindarkan manusia dari masalah kesehatan seperti penyakit maupun kekurangan gizi.

\section{Status Gizi}

Berdasarkan tabel 4 yang telah dijabarkan diatas, diperolah hasil dari 57 responden yang dilakukan pengukuran status gizi dengan $\mathrm{BB} / \mathrm{U}$, sebanyak 26 responden $(45,6 \%)$ dengan status gizi kurang. Data ini menunjukkan bahwa sebagian besar bayi di wilayah Beji Sidoarum Godean memiliki status gizi kurang.

Menurut penelitian Evayanti, dkk (2014) menyatakan bahwa faktor yang secara langsung maupun tidak langsung dapat menjadi faktor pendorong dalam pemberian makanan pada bayi, terdiri dari faktor agent, penjamu, lingkungan dan perilaku.

\section{Hubungan pemberian makanan pendamping ASI dengan status gizi bayi usia 6- 11 bulan}

Berdasarkan hasil pengolahan data menggunakan uji Chi Square 
yang diperoleh dari 57 responden menunjukkan bahwa $\mathrm{Ha}$ diterima dan Ho ditolak yang berarti ada hubungan yang siginifikan antara perilaku pemberian makanan pendamping ASI dengan status gizi bayi usia 6-11 bulan di wilayah Beji Sidoarum Godean Sleman. Hasil uji analisa data didapatkan nilai signifikansi 0,000 dan $p$ value > 0,05 sehingga dapat disimpulkan bahwa ada hubungan antara perilaku pemberian makanan pendamping ASI dengan status gizi bayi usia 611 bulan.

Hasil penelitian penulis didukung oleh penelitian Yonatan Kristianto (2013) dengan judul "Faktor yang mempengaruhi perilaku ibu dalam pemberian makanan pendamping ASI pada bayi umur 6-36 bulan". Dengan pernyataan bahwa faktor pengetahuan ibu, pendidikan dan pekerjaan mempengaruhi perilaku ibu dalam pemberian MP-ASI.

Islam mejelaskan

pembentukan pribadi bagi anak bermula sejak dalam kandungan. Apa yang dimakan dan dilakukan oleh ibu secara tidak langsung mempengaruhi pribadi serta tingkah laku anak. Oleh karena itu Alloh SWT memerintahkan agar selama hamil ibu melakukan hal-hal yang disyareatkan oleh agama Islam. Setelah anak lahir Alloh SWT meganjurkan kepada para orang tua agar merawat anaknya dengan sempurna, di mulai dengan memberikan minuman dan makanan yang memenuhi gizi melalui air susu ibu (ASI). Oleh karena pentingnya gizi bagi pertumbuhan dan perkembangan anak, maka Alloh SWT memerintahkan para ibu untuk menyusui anaknya sampai usia dua tahun penuh ( Yusuf, 2006).

"Dan makanlah makanan yang halal lagi baik,dari apa yang Allah telah rezekikan kepadamu,dan bertakwalah kepada Allah yang kamu telah beriman kepadanya”.(QS.AL-Maidah 88)

Imam Al-Gazali pernah berpesan, hindarilah memberi makanan syubhat (meragukan) kepada anak, lebih-lebih zat yang dilarang Allah. Sebab, setitik air atau makanan yang pernah dimakan orang tua akan pindah kepada anak yang dilahirkan menjadi daging dan dalam daging itulah bibit yang merusak akhlak dan otak yang sehat, dikemudian hari

\section{KESIMPULAN}

1. Perilaku pemberian makanan pendamping ASI di wilayah Beji Sidoarum Godean dengan pemberian makanan pendamping ASI tepat sesuai dengan hasil data pada tabel 4.3 yaitu dari 57 responden yang memberikan makanan pendamping ASI, sebanyak 44 responden $(77,2 \%)$ dengan pemberian tepat.

2. Status gizi di wilayah Beji Sidoarum Godean yang dilakukan pengukuran status gizi dengan $\mathrm{BB} / \mathrm{U}$ sebagian besar mengalami status gizi kurang, sebanyak 26 responden $(45,6 \%)$.

3. Keeratan hubungan perilaku pemberian ASI dengan status gizi bayi usia 6-11 bulan di wilayah Beji Sidoarum Godean Sleman dengan nilai koefisien kontingensi korelasinya $<0,5$ 
yaitu 0,455. Sehingga dapat disimpulkan bahwa dengan demikian dapat disimpulkan bahwa keeratan hubungan koefisien kontingensi adalah sedang $(0,40-0,599)$.

\section{DAFTAR RUJUKAN}

Al-Qur'an. 2007. A-Qur'an dan Terjemahan. Surakarta : Media Insani Publishing

Anik Sulistiyanti. 2013 Hubungan Tingkat Pengetahuan Ibu Tentang Makanan Pendamping ASI Dengan Ketepatan Usia Pemberian Makanan Pendamping ASI di Puskesmas Grogol Sukoharjo

Azwar, A. 2007. Pedoman Pemberian Makanan Pendamping ASI. http://www. gizi. net /download /mp-asi.doc. Diakses : 11 Desember 2016

Depkes RI. 2011. Keluarga Menjadi Fokus Perhatian. http://www.depkes.go.id/reso urces/download/laporan/kiner ja/kinerja-kemenkes-20092011.pdf. Diakses : 11 Desember 2016

Depkes RI. 2013. Masalah Gizi di Indonesia.

http://www.depkes.go.id/reso urces/download/pusdatin/prof il-kesehatan-indonesia/profilkesehatan-indonesia2013.pdf. Diakses : 11 Desember 2016

Dinkes DIY. 2013. Prevalensi Gizi Kurang. http://www.depkes.go.id/reso urces/download/profil/PROFI L KES PROV 2011/P.Prov. DIY 11.pdf. Diakses : 11 Desember 2016
Evayanti, dkk. 2014. Faktor-Faktor Yang Berhubungan Dengan Kejadian Diare Pada Balita. Jurnal Kesehatan Lingkungan.4(2): 134 - 139.

Handayani, D., \& Wahyuni. 2012.Hubungan Dukungan Keluarga Dengan Kepatuhan Lansia Dalam Mengikuti Posyandu Lansia Di Posyandu Lansia Jetis Desa Krajan Kecamatan Weru Kabupaten Sukoharjo.Jurnal STIKES.Volume 9. Hal 4950

Krisnatuti. 2005. Menyiapkan Makanan Pendamping ASI. Jakarta: Puspa Swara.

Notoatmodjo Soekidjo. 2012.

Pendekatan Praktis

Metodologi Riset

Keperawatan. Jakarta:

Seagung Seto.

Novita D. 2015. Hubungan Karakteristik Ibu, Faktor Pelayanan

Kesehatan,Immediate

Breastfeeding dan Pemberian Kolostrum dengan Praktek Pemberian ASI eksklusif di Wilayah Kerja Puskesmas Pancoran Mas Depok Tahun

Simanjuntak, Dahlia., 2007. FaktorFaktor yang Berhubungan dengan Pemberian

Sudjana. 2012. Metode Statistika. Alfabeta: Bandung.

Sugiyono. 2011. Statistik untuk penelitian. Bandung : CV Alfabeta

Supariasa. 2012. Pendidikan Dan Konsultasi Gizi. Jakarta : EGC Yogyakarta. Penerbit Graha Ilmu.

Yonatan Kristianto. 2013. Faktor Yang Mempengaruhi 
Perilaku Ibu Dalam Pemberian MP-ASI Pada Bayi Umur 6-36 Bulan Yusuf bin Abdullah ibnu Abdil Barr yang di tahqiq oleh Musthafa bin Ahmad al-Alawi dan
Muhammad bin Abdul Kabir al-Bakri. 2006.At-Tahmid Limaa Fil Muwaththa' minal Asanid,juz 2. Tk: Muassasah al-Qurthubi. 